\title{
Blood thiamin status and determinants in the population of Seychelles (Indian Ocean)
}

\author{
Pascal Bovet, Daniella Larue, Véronique Fayol, Fred Paccaud
}

\begin{abstract}
Study objective-Micronutrient deficiencies have become rare in industrialised countries as availability of fresh food, supplementation, and fortification have improved but a less favourable situation may still prevail in many developing countries. Blood thiamin status and determinants were therefore investigated in the Seychelles in view of the high incidence of dilated cardiomyopathy and as the staple diet is polished rice that is deficient in thiamin.

Design-This was a cross sectional popu-
\end{abstract} lation study using an age and sex stratified random sample.

Setting-Seychelles Islands (Indian

Ocean).

Participants-A subsample of 206 subjects aged 25-64 years from the population of Seychelles.

Main outcome measures-Measurement of total thiamin concentration in whole blood using high performance liquid chromatography. Dietary variables measured using a face to face semi-quantitative food questionnaire.

Results-Mean (SD) whole blood thiamin concentration was $77.9(22.4) \mathrm{nmol} / 1$ and low concentration ( $<70 \mathrm{nmol} / \mathrm{l})$ was found in $37 \%$ of the subjects (95\% CI: $31 \%, 44 \%)$. Blood thiamin was significantly related to education and diet but not to age, sex, smoking, and body mass index. Blood thiamin was associated positively with meat, vegetable, salad, and tea intake and negatively with alcohol and fish intake. However, no combination of the examined variables could explain more than $15 \%$ of the observed variance in blood thiamin values.

Conclusions-These data suggest that the distribution of blood thiamin in the sampled population is shifted to lower values compared with that generally accepted as normal in European populations. Further research should establish the significance of such lower values in this specific population to facilitate clinical and public health action as necessary.

(F Epidemiol Community Health 1998;52:237-242)

Over the past decades, beriberi heart disease and other thiamin deficient disorders have decreased in many affluent countries partly because of a larger availability of thiamin rich foods and foods artificially fortified with thiamin. Consequently, beriberi has become uncommon in Western countries and now mostly concentrates in specific population groups such as alcoholics, ${ }^{12}$ institutionalised elderly patients, ${ }^{3}$ homeless ${ }^{4}$ or in patients receiving parenteral nutrition ${ }^{5}$ or receiving treatment with phenytoin ${ }^{6}$ or furosemide. ${ }^{7}$ However, low thiamin status is still frequent and beriberi endemic in many countries in Asia-mostly resulting from the consumption of diets of unfortified polished rice lacking the vitamin rich husk- ${ }^{8-10}$ Latin America, ${ }^{11} 12$ Africa, ${ }^{13-17}$ East Europe and Russia ${ }^{18}{ }^{19}$ or in the Pacific Islands. ${ }^{20}$

This study was prompted by the high incidence of dilated cardiomyopathy in Seychelles ${ }^{21} 22$ and as the staple Seychellois diet is made of polished unfortified rice. ${ }^{23}$ We therefore examined thiamin blood status in the general population of Seychelles and attempted to identify factors associated with biochemical thiamin status.

\section{Methods}

\section{THE SEYCHELLES}

The Republic of Seychelles consists of 115 islands in the Indian Ocean, about $1800 \mathrm{~km}$ east of Kenya and $1800 \mathrm{~km}$ north of Mauritius. The population has grown to 74331 people in 1994 and is mixed urban and rural with $52 \%$ under 25 years in 1994. The ethnic distribution of the population is considered to be African in $65 \%$, European (white) in $10 \%$, Asiatic in 5\%, and mixed in $20 \%{ }^{24}$ The standard of living has improved considerably in the past two decades, which is concomitant with a dramatic increase in the tourism industry after the opening of the international airport in 1971. Gross domestic product (GDP) per capita increased from US $\$ 925$ in 1976 to US $\$ 5850$ in 1994 , and the World Bank considers Seychelles to be now a middle income country.

\section{STUDY DESIGN}

The study was designed as a population based cross sectional health survey. The survey was conducted in 1994 on the island of Mahé, which is the largest island of the Seychelles and accounts for $90 \%$ of the 74331 total population of the country. A random sex and age stratified sample of the population was drawn from the 28695 Mahe residents aged 25-64 years, on the basis of a national census carried out in 1987 and subsequently regularly updated by the administrative authorities. A total of 1067 people ( 504 men and 563 women) attended the survey out of the 1226 eligible persons, a response rate of $87 \%$. Blood thiamin concentration was determined only in a subset of the original sample by selecting every day for 
Table 1 Distribution of blood thiamin (nmol/l)

\begin{tabular}{|c|c|c|c|c|c|c|c|c|c|c|}
\hline & \multirow[b]{2}{*}{ No } & \multirow[b]{2}{*}{ Mean } & \multirow[b]{2}{*}{$S D$} & \multicolumn{7}{|c|}{ Percentiles } \\
\hline & & & & 5 & 10 & 25 & 50 & 75 & 90 & 95 \\
\hline Men & 96 & 77.3 & 24.0 & 43 & 47 & 58 & 79 & 96 & 111 & 120 \\
\hline Women & 110 & 78.5 & 24.8 & 45 & 51 & 62 & 76 & 91 & 116 & 126 \\
\hline Total & 206 & 77.9 & 24.4 & 44 & 49 & 59 & 76 & 93 & 112 & 124 \\
\hline
\end{tabular}

a two month period the five first people who had blood collected (appointment time to attend the survey was given randomly to all participants). Among the 208 subjects who had thiamin measured, two cases were excluded as thiamin concentration exceeded the mean value found for the entire subsample by more than four standard deviations and as the study focused on population parameters rather than on exceptional individual findings. Therefore this study included 206 subjects.

QUESTIONNAIRE

All participants had a face to face structured interview. Intake of fruits, vegetables, salads, and carbonated soft drinks was based on the reported consumption on the previous day. Fish and meat intakes were based on the reported weekly consumption. Participants who reported to drink at least one drink per week were specifically asked about their weekly average consumption of the three commercially marketed alcoholic beverages (beer, spirits, and wine) and three commonly home brewed beverages commonly available in the country. The average alcohol content of these home brews, which are respectively made of fermented palm sap juice, sugar cane and fruit or vegetables was previously assessed and ranged from 7 to 9 grams per litre. ${ }^{21}$ The average daily intake of alcohol could be calculated from several questions on the reported type and amount of alcoholic beverages consumed during the previous week. Cigarette smoking was defined as regularly smoking at least one cigarette per day. Body mass index was calculated as weight in kilograms divided by height in metres squared.

BLOOD THIAMIN

Whole blood thiamin concentration was measured at the Laboratory of Vitamins, Marcel Mérieux Foundation (Lyon, France) using a straight phase high performance liquid chromatography (HPLC) technique developed in this laboratory that was previously described..$^{25}$ The method includes an extraction step using trichloroacetic acid and takadiastase (during which the phosphorylated forms are converted into free thiamin) and a pre-column derivatisation step (during which thiamin is converted into fluorescent thiochrome ester). Intra and inter assay reproducibility variation of the method were smaller than $7 \%$. Assays were carried out less than two months after blood was collected and blood was kept frozen at $-20^{\circ} \mathrm{C}$ in the interval, using lithium heparin as an anticoagulant. It has been previously shown that there was no loss of thiamin in blood kept frozen at $-20^{\circ} \mathrm{C} .{ }^{26}$ Reference values ( $\mathrm{nmol} / \mathrm{l}$ ) for whole blood total thiamin measured in the same laboratory were previously obtained from
50 French healthy volunteers (range: 70 to 128; mean (SD): 99 (15) (1 ng/l $=2.9$ $\mathrm{nmol} / \mathrm{l})) .^{25}$

STATISTICS

Exact binomial 95\% confidence intervals were calculated for prevalence estimates. Differences in mean values between two groups and across ordered groups were tested using $t$ test and non-parametric trend test, respectively. Relations between blood thiamin concentration and selected factors were estimated using univariate and multivariate linear regression models. Analyses were not weighted for age as blood thiamin did not relate to age in the considered age range. Analyses were performed using Stata Software 4.0 (Stata Corporation, College Station, Texas). All reported $\mathrm{p}$ values are two tailed and $p$ values less than 0.05 considered as significant.

\section{Results}

Blood thiamin ranged from 30 to $150 \mathrm{nmol} / 1$ in the study sample. Table 1 shows the mean, standard deviation, and percentiles of blood thiamin across age and sex groups. Thiamin was distributed fairly normally and was similar in men and women (Kolomogorov-Smirnov test for equality of distributions: $p=0.7$ ). Proportions of the subjects with defined blood thiamin values (nmol/l) were as follows: below 40: $2.9 \%$; 40-50: $8.2 \%$; 50-60: $14.1 \%$; 70-80: $16.5 \%$; 80-90: $16.5 \%$; 90-100: $11.1 \% ; 100$ and above: $17.5 \%$. Blood thiamin was low by French standards $(<70 \mathrm{nmol} / \mathrm{l})$ in 77 of 206 subjects - that is, a prevalence of $37 \%$ (95\% confidence intervals: $31 \%, 44 \%)$. Anaemia (which has relevance when assessing thiamin concentration in whole blood) was found in only three of 96 men and four of 110 women, using packed cell volume diagnostic criteria set at $42 \mathrm{~g} / 100 \mathrm{ml}$ in men and $37 \mathrm{~g} / 100 \mathrm{ml}$ in women.

Table 2 shows the distribution of subjects and mean blood thiamin across selected groups of population. Thiamin did not substantially vary with age and sex within our sample of adults. Thiamin was lower in people who had not attended secondary school compared with those who had. Thiamin was positively associated with intake of meat, vegetable, salad, and tea and negatively with intake of alcohol and fish. Alcohol consumed by heavy drinkers originated fairly equally from homemade brews and commercially marketed beverages (data not shown). Although around $87 \%$ of the population reported to eat fish every day in average, $95 \%$ reported to almost never eat raw fish. Thiamin did not differ across categories of smoking, body mass index, fruit intake, and vitamin supplement intake not otherwise specified.

Table 3 shows results of univariate and multivariate linear regression analyses of selected factors on blood thiamin. Analyses were carried out using indicator variables. In these analyses, regression coefficients $(\beta)$ indicate the predicted change in blood thiamin associated with the change of the explanatory variable (for example, thiamin is $12.8 \mathrm{nmol} / 1$ lower in people 
Table 2 Distribution of blood thiamin across categories of selected demographic, clinical, and dietary variables

\begin{tabular}{|c|c|c|c|c|}
\hline & No & Mean & $S D$ & $p$ value \\
\hline \multicolumn{5}{|l|}{ Age } \\
\hline $25-44$ & 108 & 79.5 & 22.6 & \\
\hline $45-64$ & 98 & 76.2 & 26.1 & NS \\
\hline \multicolumn{5}{|l|}{ Sex } \\
\hline Women & 110 & 78.5 & 24.8 & \\
\hline Men & 96 & 77.3 & 24.0 & NS \\
\hline \multicolumn{5}{|l|}{ Education after primary level } \\
\hline No & 169 & 74.9 & 23.2 & \\
\hline Yes & 37 & 91.7 & 25.0 & 0.000 \\
\hline \multicolumn{5}{|l|}{ Smoking } \\
\hline No & 155 & 78.8 & 25.4 & \\
\hline Yes & 51 & 75.3 & 20.9 & NS \\
\hline \multicolumn{5}{|l|}{ Body mass index $\left(\mathrm{kg} / \mathrm{m}^{2}\right)$} \\
\hline Less than 25 & 122 & 78.6 & 23.8 & \\
\hline $25-29$ & 44 & 75.1 & 25.4 & \\
\hline 30 and above & 40 & 78.9 & 25.2 & NS \\
\hline \multicolumn{5}{|l|}{ Fish servings per day } \\
\hline Less than 1 & 26 & 90.6 & 26.4 & \\
\hline 1 and above & 180 & 76.1 & 23.6 & 0.004 \\
\hline \multicolumn{5}{|l|}{ Meat servings per week } \\
\hline Less than 1 & 48 & 84.1 & 24.9 & \\
\hline 1 and above & 158 & 76.1 & 24.0 & 0.047 \\
\hline \multicolumn{5}{|l|}{ Number of fruits on previous day } \\
\hline 0 & 108 & 77.0 & 23.8 & \\
\hline 1 and above & 98 & 79.0 & 25.0 & NS \\
\hline \multicolumn{5}{|l|}{ Vegetable servings on previous day } \\
\hline 0 & 72 & 73.4 & 24.5 & \\
\hline 1 & 63 & 74.6 & 23.1 & \\
\hline 2 and above & 71 & 85.6 & 23.8 & 0.000 \\
\hline \multicolumn{5}{|l|}{ Salad servings on previous day } \\
\hline 0 & 114 & 75.2 & 23.2 & \\
\hline 1 & 66 & 77.2 & 22.6 & \\
\hline 2 and above & 26 & 91.5 & 29.8 & 0.021 \\
\hline \multicolumn{5}{|l|}{ Cups of tea per day on average } \\
\hline $0-1$ & 51 & 72.3 & 24.1 & \\
\hline $2-3$ & 110 & 77.0 & 23.5 & \\
\hline 4 and above & 45 & 86.6 & 24.8 & 0.002 \\
\hline \multicolumn{5}{|c|}{ Gram of alcohol per day on average } \\
\hline 0 & 155 & 79.2 & 27.9 & \\
\hline $1-99$ & 25 & 82.1 & 21.7 & \\
\hline 100 and above & 26 & 66.4 & 20.7 & ns \\
\hline \multicolumn{5}{|c|}{ Vitamin supplement or yeast paste } \\
\hline No intake within last weeks & 160 & 76.6 & 23.4 & \\
\hline Intake within last weeks & 46 & 82.7 & 27.3 & ns \\
\hline
\end{tabular}

^Differences between categories are tested with $t$ test ( 2 categories) or test for trend ( 3 categories).

Table 3 Linear regression of various demographic and dietary variables on blood thiamin

\begin{tabular}{|c|c|c|c|c|}
\hline & \multicolumn{2}{|c|}{ Univariate } & \multicolumn{2}{|c|}{$\begin{array}{l}\text { Multivariate } \\
\left(\text { Adjusted } r^{2}=0.12\right)\end{array}$} \\
\hline & $\beta$ & p value & $\beta$ & $p$ value \\
\hline Age $(45-64$ v 25-44) & -3.2 & NS & - & - \\
\hline Sex (men $v$ women) & -1.1 & NS & - & - \\
\hline Education after primary level (yes $v$ no) & 16.8 & 0.000 & - & - \\
\hline Fish servings per day $(\geqslant 1 v<1)$ & -14.5 & 0.004 & -9.8 & 0.055 \\
\hline Meat servings per week $(\geqslant 1 v<1)$ & 8.0 & 0.047 & 4.5 & NS \\
\hline Fruit number on previous day $(\geqslant 1 v 0)$ & 2.1 & NS & -1.8 & NS \\
\hline \multicolumn{5}{|l|}{ Vegetable servings on previous day $(v 0)$} \\
\hline 1 & 1.2 & NS & -1.6 & NS \\
\hline 2 and above & 12.2 & 0.002 & 7.6 & 0.060 \\
\hline \multicolumn{5}{|l|}{ Salad servings on previous day $(v 0)$} \\
\hline 1 & 1.9 & NS & 2.6 & NS \\
\hline 2 and above & 16.1 & 0.002 & 12.2 & 0.022 \\
\hline \multicolumn{5}{|l|}{ Cups of tea per day on average $(v 0-1)$} \\
\hline $2-3$ & 4.7 & NS & 2.9 & NS \\
\hline 4 and above & 14.2 & 0.004 & 11.9 & 0.012 \\
\hline \multicolumn{5}{|l|}{ Gram of alcohol per day on average $(v 0)$} \\
\hline $1-99$ & 2.8 & NS & 2.5 & NS \\
\hline 100 and above & -12.8 & 0.013 & -9.6 & 0.057 \\
\hline Vitamin or yeast within last weeks (yes $v$ no) & 6.2 & NS & 1.9 & NS \\
\hline
\end{tabular}

$\beta=$ regression coefficient. The multivariate model includes all listed variables as dependent variables. adjusted $r^{2}$ of the multivariate model. Adjustment for education in addition to the dietary variables increased the explained variance to $15 \%$ but the magnitude of the regression coefficients of most dietary items slightly decreased, indicating that the effect of education on blood thiamin was partly conveyed by these dietary items (data not shown).

\section{Discussion}

This study showed that mean whole blood thiamin concentrations were substantially lower in the adult population of Seychelles compared with European populations where whole blood thiamin was similarly measured. For example, mean (SD) blood thiamin was substantially lower in the Seychelles population than in a series of 50 healthy French adults who had thiamin determined using the same technique carried out in the same laboratory $(78(24) v 99(15) \mathrm{nmol} / \mathrm{l} ; \mathrm{p}<0.001)^{25}$ or in a series of 56 healthy Dutch adults, using the same technique performed in another laboratory $(78 v 117 \mathrm{nmol} / \mathrm{l}) .{ }^{26}$ While blood thiamin (nmol/1) ranged from 30-150 in the sample in Seychelles, ranges were $70-128$ in the French study, 71-157 in the Dutch study, and 70-185 in a first published study. ${ }^{27}$ These findings suggest that a substantial proportion of the adult population of Seychelles has low blood thiamin compared with European populations. This proportion may amount to one third of adults if low values are considered for whole blood thiamin below $70 \mathrm{nmol} / 1$, which corresponds to the cut off values suggested by all three mentioned European studies.

Direct measurement of blood thiamin by HPLC is considered to provide a reliable and accurate method for assessing long term thiamin nutritional status. ${ }^{28-30}$ Low thiamin blood concentrations in the population may relate to clinical findings of a high incidence of dilated cardiomyopathy of unclear origin ${ }^{21} 22$ and with findings from two Household Expenditure Surveys carried out in Seychelles in 1984 and 1993 indicating that purchased foods satisfied less than $80 \%$ of recommended thiamin requirements. ${ }^{23}$ Major factors that probably contribute to low thiamin concentrations are the staple Seychellois diet, which is unfortified polished rice, the fact that carbohydrates account for a high proportion (around $62 \%$, excluding alcohol) of the total energy intake of the Seychellois diet, ${ }^{23}$ and that a substantial proportion of the population drinks large amount of alcohol ( $>15 \%$ of male adults drink more than $100 \mathrm{~g}$ of ethanol per day $^{31}$ ). Thus, biochemical and dietary data provide strong evidence for low thiamin concentrations in the population.

Sex and age did not relate significantly to thiamin blood values, which is consistent with reported findings of other studies in adults ${ }^{32}$ although higher concentrations of thiamin were also described in men compared with women. ${ }^{33}$ Lower blood thiamin was found in people with lower education attainment, which is consistent with other studies on the effect of socioeconomic status on blood thiamin. ${ }^{36}{ }^{37}$ These relations may be partly explained by dietary factors 
because education is a recognised determinant of dietary patterns. ${ }^{38}$ Our results support the view that the effect of education on blood thiamin is partly mediated by dietary factors as the magnitude of the regression coefficients of most dietary variables relating to thiamin decreased after adjusting for education.

The negative association between alcohol and thiamin found in our study is also consistent with reports that heavy alcohol drinkers have lower thiamin values and low thiamin intake is related to decreased food intake and reduced thiamin intestinal absorption. ${ }^{12}$ The associations of higher thiamin values with vegetable, salad, and meat found in this study are consistent with these foods containing substantial amounts of thiamin. The negative relation found between fish and thiamin, although fish contains fair amounts of thiamin, may be an artefact explained by the small between individuals variability of fish intake in the country- $90 \%$ of the population eat fish every day-and residual confounding as fish correlated positively with alcohol (which relates negatively to thiamin) and negatively with meat and vegetables (which both relate positively to thiamin). An effect caused by anti-thiamin activity in fish is unlikely as such an antithiamin activity has been reported in raw or fermented fish ${ }^{39-41}$ both of which are almost never consumed in Seychelles. Tea has also been reported to be associated with low blood thiamin caused by thiaminase, inhibition of thiamin utilisation, reduced urinary excretion of thiamin, and reduced erythrocyte transketolase activity. ${ }^{42}{ }^{43}$ In Seychelles where tea is consumed in ample amounts (2.6 (SD1.8) cups per day on average in our study) we found a positive relation instead. Although confounding by alcohol intake and other variables may not be excluded, it is unlikely that such a bias could entirely account for the observed positive association, which suggests that tea consumed in Seychelles does not contain substantial antithiamin activity.

Overall, dietary factors predicted blood thiamin rather poorly in our study as no combination of the considered dietary variables could explain more than $11 \%$ of the variance of blood thiamin. This does not come as a surprise as several other studies in other populations were unable to demonstrate an association between blood thiamin and thiamin intake as assessed by food questionnaire. ${ }^{28} 444^{45}$ Weak or null association with thiamin intake is consistent with the fairly uniform distribution of thiamin in foods ${ }^{46}$ and the difficulty to account for thiamin losses as a result of thiamin leaching in cooking water and thiamin cleavage by heat. ${ }^{4-49}$

With regard to clinical practice, our data suggest that thiamin can be given to patients with heart failure of unclear origin, in view of the high mortality of untreated cardiovascular beriberi, the dramatic efficacy of thiamin supplementation in such cases, and in view of the harmless nature of thiamin supplementation.

From a public health view, this study suggests that a substantial proportion of the adult population of Seychelles has low thiamin status compared with European adult populations. The data also indicate that thiamin deficiency cannot be accurately predicted using sociodemographic or dietary indicators. Prevention of thiamin deficiency may therefore target the entire population. Health education to change the population diet in this regard is desirable in view of various health implications. However dietary behaviours are deeply ingrained in the culture and will be slow to change at best. In addition, there are in all populations minorities with limited purchasing power (alcoholics or unemployed being examples) who may have material difficulties to adopt a fully satisfactory diet. Furthermore, a well balanced diet does not provide thiamin in excess, and thiamin cannot be stored in the body in great extent because of its short half life (1.8 days). ${ }^{50}$ Therefore dietary fortification (the addition of micronutrients to foods in processing) may be the best long term strategy in controlling micronutrient deficiency where essential micronutrient deficiency is prevalent. ${ }^{51}$ Fortification programmes have been implemented by many countries, mostly industrialised, and a variety of foods have been supplemented with thiamin such as rice, ${ }^{52}$ cereals $^{53}$ or flour. ${ }^{54}$ In the UK for example, breakfast cereals, most of which are fortified with thiamin and other micronutrients, was shown to account for more than $25 \%$ of dietary thiamin $^{44}$ and it is now considered that withdrawal of thiamin fortification from processed cereals would have serious negative implications for public health. ${ }^{53}$ In developing countries, food fortification with nutrients should similarly be considered a public health priority because gradual replacement of traditional cereals with, for example, milled rice increases susceptibility to beriberi ${ }^{17}$ and thiamin status may further be worsened by the recent tendency, particularly for teenagers, to take excessive sweet carbonated soft drinks, instant prepared carbohydrate food, which can readily induce relative thiamin deficiency. ${ }^{9}$

As it is well established that heavy alcohol drinkers are at particularly high risk of developing beriberi, ${ }^{56-58}$ special prevention efforts should target this segment of population. To this end, fortification programmes of alcohol beverages have been implemented in various countries. ${ }^{535960}$ Alcohol beverage fortification does not materially affect the price of the product ${ }^{61}$ nor the taste, ${ }^{62}$ and bioavailability of thiamin from this source is high, for example 55 to $103 \%$ of the added vitamin in wine after 21 months of storage. ${ }^{63}$ Homemade brews will obviously escape fortification attempts but the data in Seychelles indicate that drinkers of home brews also drink beer in large amount. A cost-benefit analysis of the fortification programme recommended in Australia by the National Health and Medical Research Council, which consists of adding thiamin to flour, wines, and beer, was shown to have, under a range of various plausible assumptions, a costbenefit ratio as high as $6: 1$ to $30: 1$ so that the programme is also supported strongly on economic grounds. ${ }^{64}$ 
KEY POINTS

- Thiamin deficiency may occur in communities with a diet rich in polished rice and poor in fortified foods.

- The trend to replace the traditional diet by carbohydrate foods and carbonated drinks may increase the susceptibility to thiamin deficiency.

- Thiamin deficiency is poorly predicted using dietary or socioeconomic indicators at the individual level.

- Routine thiamin supplementation should be considered in patients with heart failure of unclear origin in communities where thiamin deficiency is suspected.

- Food fortification is a long term strategy of choice in controlling thiamin and other remediable micronutrients deficiencies in populations.

In conclusion, these data suggest that there may be a problem related to low thiamin concentrations in the adult population, which requires national attention because, if this is confirmed, it could have significant health implications. More generally, the data emphasise that thiamin deficiency, and possibly other remediable micronutrient deficiencies, may still be of considerable public health importance in various communities.

The authors wish to thank Anne Rwebogora, George Madeleine, and Judy Brioche (Ministry of Health, Seychelles) for their assistance in the study; Dr Samuel Brew-Graves and Dr Conrad Shamlaye (Ministry of Health, Seychelles) for valuable comments on earlier drafts; and the Ministry of Health of Seychelles for its support to health research.

Funding: Pascal Bovet benefits from a grant by the Swiss National Foundation for Science (No. 3233-038792.93).

1 Tallaksen CM, Bell H, Bohmer T. The concentration of thiamin and thiamin phosphate esters in patients with alcoholic liver cirrhosis. Alcohol Alcohol 1992;27:523-30.

2 Hoyumpa AM. Mechanisms of thiamin deficiency in chronic alcoholism. Am f Clin Nutr 1980;33:2750-61.

3 O'Rourke NP, Bunker VW, Thomas AJ, Finglas PM, Bailey AL, Clayton BE. Thiamine status of healthy and institutionalized elderly subjects: analysis of dietary intake and biochemical indices. Age Ageing 1990;19:325-9.

4 Darnton-Hill I, Truswell AS. Thiamin status of a sample of homeless clinic attenders in Sydney. Med F Aust 1990;152 5-9.

5 Klein G, Probst S, Kessler P, A, et al. Thiamine deficiency as a cause of life threatening lactic acidosis in total parenteral nutrition. Klin Wochenschr 1991;69 (suppl 26):193-5.

6 Botez MI, Botez T, Ross Chouinard A, Lalonde R. Thiamine and folate treatment of chronic epileptic patients: a controlled study with the Wechsler IQ scale. Epilepsy Res 1993;16:157-63.

7 Shimon I, Almog S, Vered Z, et al. Improved left ventricular function after thiamine supplementation in patients with function after thiamine supplementation in patients with congestive heart failure receiv
Am $\mathcal{Y}$ Med 1995;98:485-90.

8 Djoenaidi W, Notermans SL, Dunda G. Beriberi cardiomyopathy: a study in Indonesia. Eur $\mathcal{f}$ Clin Nutr 1992;46:227-34.

9 Kawai C, Wakabayashi A, Matsumara T, Yui Y. Reappearance of beriberi heart disease in Japan: a study of 23 cases. Am 7 Med 1980;69:383-6.

10 Pongpanich B, Srikikkrich N, Dhanamitta S, Valyasevi A Biochemical detection of thiamin in infants and children in Thailand. Am f Clin Nutr 1974;27:1399-402.

11 Hailemariam B, Landman JP, Jackson AA. Thiamin status in normal and malnourished children in Jamaica. $\mathrm{Br} \mathcal{F}$ Nutr 1985;53:477-83.

12 Fernandez NA, Burgos JC, Roberts LJ, Asenjo CF Nutritional status in Puerto Rican slum area. Am $\mathrm{f}$ Clin Nutr 1968;21:646-56.

13 van der Westhuyzen J, Davis RE, Icke GC, Jenkins T. Thiamin status and biochemical indices of malnutrition and alcoholism in settled of !Kung San. F Trop Med Hyg 1987; 90:283-9.
14 Naidoo DP, Gathiram V, Sadhabiriss A, Hassen F. Clinical diagnosis of cardiac beriberi. $S$ Afr Med $\mathscr{f} 1990 ; 77: 125-7$. diagnosis of cardiac beriberi. S Afr Med $f$ 1990;77:125-7.
Fashakin JB, Oyekanmi MA. Evaluation of some vitamin Fashakin JB, Oyekanmi MA. Evaluation of some vitamin
B-complex in Ile-Ife and environs (Nigeria). Int $\mathcal{F}$ Vit Nutr Res 1996;56:79-84.

16 Watson JD, Dako DY. Erythrocyte transketolase activity in adult Ghanaian subjects. Clin Chem Acta 1975;59:55-61.

17 Tang CM, Rolfe M, Wells JC, Cham K. Outbreak of beri-beri in the Gambia. Lancet 1989;ii:206-7.

18 Piptelite OS, Aleinik SI, Iakushina LM, et al. The provision of vitamins to school children in rural regions of Lithuania. Vopr Pitan 1992;4:32-5.

19 Isaeva VA, Sokolnikov EA, Alekseeva IA, Aleinik SI, Blazheevich NV, Spirichev VB. Providing with vitamins of different population groups in Sverdlovsk. Vopr Pitan 1992;

20 Duffy P, Morris H, Neilson G. Thiamin status of the Melanesian population. Am f Clin Nutr 1981;34:1584-92.

21 Pinn G, Bovet P. Alcohol related cardiomyopathy in the Seychelles. Med f A ust 1991;155:529-32.

22 Bovet $\mathrm{P}$, for the Investigators of the Seychelles Heart Study. The epidemiologic transition to chronic diseases in developing countries: cardiovascular mortality, morbidity, and risk factors in Seychelles (Indian Ocean). Soz Praventivmed 1995;40:35-43.

23 Larue D. Food consumption patterns in the Seychelles between 1983 and 1993. Seychelles Medical and Dental fournal 1995;4:16-19.

24 Bovet P, Rosalie D, Shamlaye C, Darioli R, Paccaud F. The Seychelles Cardiovascular Disease Study. Soz Praeventivmed 1991;36 (suppl 1):S3-7.

25 Laschi-Loquerie A, Vallas S, Viollet J, Leclercq M, Fayol V. High performance liquid chromatography determination of total thiamine in biological and food products. Int $\mathcal{F}$ Vit total thiamine in biological
Nutr Res $1991 ; 62: 248-51$.

26 Wielders JPM, Mink CJK. Quantitative analysis of total thiamine in human blood, milk and cerebrospinal fluid by thiamine in human blood, milk and cerebrospinal fluid by
reversed-phase ion-performance liquid chromatography. $\mathcal{f}$ reversed-phase ion-performance

27 Schrijver J, Speek AJ, Klosse JA, van-Rijn HJ, Schreurs WH. A reliable semiautomated method for the determination in whole blood by the thiochrome method. Ann Clin Biochem 1982;19:52-6.

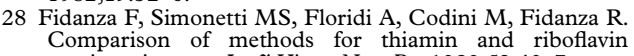
nutriture in man. Int $\mathcal{F}$ Vitam Nutr Res 1989;59:40-7.

29 Herve C, Beyne P, Letteron P, Delacoux E. Comparison of erythrocyte transketolase activity with thiamine and thiamine phosphate ester levels in chronic alcoholic patients. Clin Chem Acta 1995;234:91-100.

30 Baines M, Davies G. The evaluation of erythrocyte thiamin diphosphate as an indicator of thiamin status in man, and its comparison with erythrocyte transketolase activity its comparison with erythrocyte transketolase activ

31 Bovet P. Drinking habits and related clinical findings in the Seychelles. Soz Praventivmed 1991;36 (suppl 1):16, 60-2.

32 Icke G, Nicol D. Automated microbiological assay of thiamin in serum and red cells. F Clin Pathol 1994;47:63941 .

33 Herbeth B, Zittoun J, Miravet L, et al. Reference intervals for vitamins B1, B2, E, D, retinol, beta-carotene, and folate
in blood: usefulness of dietary selection criteria. Clin Chem 1986;32:1756-9.

34 Wyatt DT, Nelson D, Hillman RE. Age-dependent changes in thiamin concentration in whole blood and cerebrospinal fluid in infants and children. Am F Clin Nutr 1991;53:530-

Cromer BA, Wyatt DT, Brandstaetter LA, Spadone S, Sloan HR. Thiamine status in urban adolescents: effects of race. f Pediatr Gastroenterol Nutr 1989;9:502-6.

36 McKenzie J. The impact of economic and social status on food choice. Proc Nutr Soc 1974;33:67-73.

37 Kerr GR, Lee ES, Lam MK, et al. Relationship between dietary and biochemical measures of nutritional status in HANES I data. Am f Clin Nutr 1982;35:294-307.

38 Roos E, Prattala R, Lahelma E, Kleemola P, Pietinen P. Modern and healthy?: socioeconomic differences in the quality of diet. Eur F Clin Nutr 1996;50:753-60.

39 Hilker DM, Peter OF. Anti-thiamine activity in Hawaii fish. f Nutr 1966;89:419-21.

40 Hilker DM, Peter OF. Studies on antithiamine factor(s) in tissue of tuna and goatfish. Experientia 1968;24:1146-7.

41 Vimokesant SL, Hilker DM, Nakornachai S, Rungruangsak $\mathrm{K}$, Dhanamitta S. Effects of betel nut and fermented fish on the thiamin status of northeastern Thais. Am f Clin Nutr 1975;28:1458-63.

42 Murata K. Thiaminase. In: Shimazono N, Katsura E, eds. Review of Japanese literature on beri-beri and thiamine. Tokyo: Igaku Shoin, 1978:220-54.

43 Wang RS, Kies C. Niacin, thiamin, iron and protein of humans as affected by the consumption of tea (Camellia sinensis) infusions. Plant Foods Hum Nutr 1991;41:337-53.

44 Bailey AL, Finglas PM, Wright AJ, Southon S. Thiamin intake, erythrocyte transketolase activity and total erythrocyte thiamin in adolescents. Br $\mathcal{F}$ Nutr 1994;72:111-25.

45 Nichols HK, Basu TK. Thiamin status of the elderly: dietary intake and thiamin pyrophosphate response. $7 \mathrm{Am}$ Coll Nutr 1994;13:57-61.

46 Sauberlich HE, Herman YF, Stevens CO, Herman RH. Thiamin requirement of the adult human. Am f Clin Nutr 1979;32:2237-48

47 Kimura M, Itokawa Y, Fujiwara M. Cooking losses of thia$\mathrm{min}$ in food and its nutritional significance. $\mathcal{F}$ Nutr Sci Vitaminol Tokyo 1990;36 (suppl 1):S17-24. 
48 Ayranci G, Kaya S. Kinetic analysis of the loss of some B-vitamins during the cooking of macaroni. Nahrung B-vitamins during

49 Abdel-Kader ZM. Studies on some water-soluble vitamins retention in potatoes and cow peas as affected by therma processing and storage. Nahrung 1990;34:899-904.

50 Royer-Morrot MJ, Zhiri A, Paille F, Royer RJ. Plasma thiamine concentrations after intramuscular and oral multiple dosage regimens in health men. Eur f Clin Pharmacol 1992; 42:219-22.

51 Levin HM, Pollitt E, Galloway R, McGuire J. Micronutrients deficiency disorders. In: Jamison DT, Mosley WH, Measham AR, Bobadilla JL, eds. Disease control priorities in developing countries. New York: Oxford University Press, 1993:421-51.

52 Gershoff SN, McGandy RB, Suttapreyasri D, et al. Nutrition in Thailand. Effects of fortification of rice with lysine, threonine, thiamin, riboflavin, vitamin $\mathrm{A}$, and iron lysine, threonine, thiamin, riboflavin, vitamin A, and iron
on preschool children. Am f Clin Nutr 1977;30:1185-95.

53 Anderson SH, Vickery CA, Nicol AD. Adult thiamine requirements and the continuing need to fortify processed requirements and the contin.
cereals. Lancet 1986;ii: $85-9$.

54 Anonymous. Fortified flour. [Editorial]. Lancet 1975;ii: 401-2.

55 Kamien M, Woodhill JM, Nobile S, Cameron P, Rosevar P. Nutrition in the Australian aborigines: effects of the fortification of white flour. Aust NZF Med 1975;5:123-33.
56 Pereira VG, Masuda Z, Katz A, Tronchini V. Shoshin beriberi: report of two successfully treated patients with hemodynamic documentation. Am $\mathcal{F}$ Cardiol 1984;53:1467.

57 Campbell CH. The severe lactacidosis of thiamine deficiency: acute pernicious or fulminating beriberi. Lancet 1984;ii:446-9.

58 Whyte KF, Dunnigan MG, McIntosh WB. Excessive beer consumption and beri-beri. Scott Med $\mathcal{F}$ 1982;27:288-91.

59 Birkbeck J. Fortification of beer and bread. N Z Med f 1988; 101:27-8.

60 van der Westhuyzen J, Davis RE, Icke GC, Metz J. Thiamine deficiency in black male hostel-dwellers. The need for thiamine supplementation of sorghum beer. $S$ Afr Med F 1987; 71:231-4.

61 Meilgaard MC. Technical aspects of the enrichment of beer with thiamine. F Stud Alcohol 1982;43:427-33.

62 Bishai DM, Bozzetti LP. Current progress toward the prevention of the Wernicke-Korsakoff syndrome. Alcohol Alcohol 1986;21:315-23.

63 Nixon P, Price J, Jago J, Davis R. The stability of thiamine and thiamine tetrahydrofurfuryl disulfide added to table wines. F Nutr Sci Vitaminol Tokyo 1991;37:201-6.

64 Fischer AJ, Yellowlees PM. Prevention of the WernickeKorsakoff syndrome in Australia: a cost-benefit analysis. Med F Aust 1989;150:311-13. 